\title{
Recursos digitais e não-digitais na aprendizagem do conceito de medida
}

\author{
Elisa Friedrich Martins ${ }^{1}$
}

\begin{abstract}
Resumo: O presente trabalho apresenta uma proposta elaborada e implementada que discute o conceito de medida e faz uso integrado de materiais manipulativos digitais e não-digitais. As atividades realizadas com os alunos são descritas e os resultados analisados com base na teoria dos Campos Conceituais de Vergnaud. O desenvolvimento da proposta mostra que o uso de materiais diversificados proporciona que os alunos, utilizando estratégias e recursos distintos, vivenciem as mesmas experiências. Além disso, a proposta mostrou-se consistente, apresentando contribuição para a aprendizagem dos alunos e o envolvimento dos mesmos nas atividades.
\end{abstract}

Palavras-chave: medida, objeto digital de aprendizagem, ensino de matemática, materiais manipulativos

\section{Digital and non-digital Resources for learning of concept of measure}

\begin{abstract}
This paper presents a proposal prepared and implemented that discuss the concept of measurement and uses, an integrated way, manipulative digital and nondigital resources. The activities with students are described and the results are analyzed based on the theory Vergnaud's Conceptual Fields. The development of the proposal shows that the use of different materials provides students, using different strategies and resources, pass through the same experiences. In addition, the proposal was consistent, presenting contribution to student learning and their involvement in the activities.
\end{abstract}

Key-words: measurement, digital learning object, mathematics education, manipulative materials

\section{Introdução}

Os Parâmetros Curriculares Nacionais (PCNs) propõem o trabalho com medidas desde os primeiros ciclos do Ensino Fundamental. Entre os conteúdos apontados nesse material aparecem: 1. comparação de grandezas de mesma natureza, com escolha de uma unidade de medida da mesma espécie do atributo a ser mensurado; 2. estabelecimento das relações entre unidades usuais de medida de uma mesma grandeza; 3. estabelecimento de conversões entre algumas unidades de medida mais usuais (para comprimento, massa, tempo) em resolução de situações-problema; 4. utilização de instrumentos de medida, como régua, trena, cronômetros, balanças, selecionando os instrumentos e unidades de medida adequadas à precisão que se requerem, em função da situação-problema.

1 PPGEMat - Programa de Pós-Graduação em Ensino de Matemática - UFRGS - Email: titamat@yahoo.com.br 
Além disso, outros professores -autores vêm defendendo o uso integrado de materiais manipulativos digitais e não-digitais na abordagem de conceitos de matemática apresentando e publicando relatos de experiência em eventos e periódicos relativos ao tema. No ano de 2010 foram publicados na Revista Novas Tecnologias na Educação (RENOTE) dois artigos nessa linha: O Uso Associado de Recursos Manipulativos Digitais e Não-Digitais para o Ensino- Aprendizagem de Matemática de Aline Fraga da Rosa; O uso do software Google Sketchup e de material concreto para a aplicação de conceitos adquiridos nas aulas de matemática - de Larissa Weyh Monzon. Existe, na internet, um repertório de objetos e softwares que abordam conceitos de Matemática e que podem ser explorados. Os alunos, em geral, se interessam por atividades no computador, mas pouco conhecem as ferramentas disponíveis e os materiais educacionais. A partir disso, foi elaborada e implementada, no ano de 2010, uma proposta que utiliza, de forma intercalada, objetos digitais e nãodigitais desenvolvidos para o ensino e aprendizagem de medidas no $6^{\circ}$ ano de Ensino Fundamental.

O objetivo inicial de trabalhar medidas era operar com números decimais a partir de questões práticas. Após constatar que os alunos não dominavam o conceito de medida de comprimento, a proposta foi trabalhar concomitantemente os números decimais e as medidas, uma vez que as unidades de comprimento, capacidade e volume do Sistema Internacional de Unidades (SI) estão em base decimal. Além de utilizar palitos de picolé e a régua - unidades não-usuais e usuais - foi utilizado um objeto digital de aprendizagem que está disponível na internet e que trabalha com unidades não-usuais de medida de comprimento: o BaBeBi. Conforme Hoffmann (2009, pp. 2-3)

Recursos manipulativos, digitais e não-digitais, podem possibilitar a exploração de propriedades observáveis pelas crianças, pois, quanto mais diversificadas forem as formas (objetos virtuais, objetos não-virtuais, desenhos, produções textuais, etc.) com as quais os alunos tenham oportunidade de manipulação livre e experimentação a fim de conhecer o objeto, operar com suas propriedades, quanto maiores forem as trocas entre os pares e com o professor, nas quais estão incluídos conteúdos atitudinais (trabalho em equipe, cooperação, respeito, solidariedade, etc), quanto mais situações-problema, nas quais os alunos encontrem significado e possam se envolver criativamente, maiores as probabilidades de que esses conceitos sejam aprendidos e não simplesmente decorados para serem repetidos.

A Matemática é para o aluno, muitas vezes, um conjunto de regras ou relações que devem ser memorizadas para depois serem reproduzidas, aos professores, em avaliações. É o caso das tabelas de múltiplos e submúltiplos do metro. Apresentando o mesmo conceito - medida de comprimento - usando diferentes materiais manipulativos estamos variando a representação do conceito, como sugere Vergnaud (1993) e possibilitando que o aluno crie hipóteses e consiga testá-las. Além disso, oportunizamos que os alunos com diferentes interesses sintam-se contemplados. Grande parte dos livros didáticos sugere que se introduza esse conceito usando medidas não-usuais como palitos, materiais escolares ou mesmo partes do corpo. Sendo assim, essa poderia ser uma atividade bastante comum e nada inédita. Porém, os alunos envolvidos estavam no $3^{\circ}$ ciclo do Ensino Fundamental e não demonstravam afinidade com o conceito de medida.

Ao questionar os alunos sobre como medir a largura da porta, muitos não sabiam responder adequadamente como poderiam proceder usando palitos ou a régua. Ficou 
claro que antes de trabalhar com as unidades de medida do SI era preciso compreender o conceito de medida. Compreendido o conceito, esperava-se que fosse possível transpô-lo para diferentes grandezas e reconhecer que existem diferentes unidades.

$\mathrm{O}$ texto apresenta a proposta implementada com quatro turmas de $6^{\circ}$ ano do Ensino Fundamental em uma escola da Rede Municipal de Ensino de Porto Alegre. Os alunos, na faixa etária entre 10 e 14 anos, demonstram grande interesse pelas atividades fora da sala de aula - Laboratório de Ciências, Laboratório de Informática, pátio etc. O trabalho foi desenvolvido nos períodos de Matemática, que eram quatro por semana, e organizado de forma a intercalar momentos na sala de aula - desenvolvendo conteúdos relativos a números decimais e problemas envolvendo medidas de comprimento - e em ambientes diferentes - com experimentos práticos e buscando soluções para problemas reais. Usar os recursos digitais existentes é um desafio para os professores e o uso concomitante de material digital e não-digital vem sendo apontado como alternativa para a exploração da tecnologia disponível atualmente. Nas próximas sessões serão explicitados o uso de cada recurso bem como a integração entre eles.

\section{Uso do recurso não digital}

Partiu-se de algumas questões para os alunos

- o que é medida?

- o que pode ser medido?

- como podemos medir a porta?

- o que podemos medir na porta?

As respostas foram mostrando que eles conheciam instrumentos de medida - pois sugeriram usar uma trena ou a régua -, que sabiam de outras grandezas mensuráveis além do comprimento - pois falaram que poderíamos medir a temperatura e o peso de uma pessoa, o tempo que leva um nadador para atravessar a piscina, a velocidade que um carro passa por um pardal etc - e que não conseguiam explicar oralmente o que era medida. Seria um número? A resposta que lhes saía a boca era "o tamanho". Ao longo da discussão e das respostas apresentadas chegou-se ao consenso de que medir seria comparar uma unidade conhecida com a grandeza a ser medida.

Aparentemente resolvida a parte teórica, era necessário resolver problemas práticos. Tarefa (resolvida coletivamente): medir a largura da porta da sala de aula usando palitos de picolé. O enunciado simples está acompanhado de questões importantes: Quantos palitos são necessários para fazer a medição?

Não foram poucos os alunos que disseram que precisariam de "uns 15 palitos". Debatendo com a turma verificou-se que eram necessários apenas dois palitos e ir alinhando - e contando - um ao lado do outro de uma extremidade até a outra. Esse "alinhar" dos palitos deveria ser feito de modo paralelo ao chão, pois uma linha inclinada daria uma resposta diferente. Ainda juntos, deveriam pensar sobre o que aconteceria com a medida se fossem utilizados canudos de plástico ao invés de palitos. Nesta faixa etária, os alunos já conservam o comprimento (Piaget, 1962) e estavam convictos que a largura da porta era a mesma. Efetuando a medição verificaram que o valor da medida não era o mesmo. Por que teriam encontrado um valor menor se a mesma coisa foi medida e isso foi feito com o mesmo esquema de ação? Porque a unidade de medida foi modificada. Sendo o canudo de plástico mais comprido que o 
palito de picolé era preciso alinhar menos canudos para cobrir a largura da porta. Os alunos, então, receberam 2 palitos de picolé e 2 canudos plásticos para medir os seguintes objetos da escola: comprimento do banco ao lado do bebedouro; comprimento da linha amarela no chão da área coberta; largura da porta da sala do xérox; altura do degrau da escada que dá acesso ao prédio da secretaria. Eles poderiam agrupar-se da maneira que achassem viável e registrar, no caderno, as medidas nas diferentes unidades: palitos e canudos.

Ao oferecer duas unidades distintas está se utilizando a unidade como um variante operatório e o comprimento como um invariante (Vergnaud, 1993). Ainda está sendo recomendado que se utilize o mesmo esquema de ação na hora de obter o resultado: alinhar palitos ou canudos ao longo de uma determinada distância. Esse esquema está bastante automatizado, os alunos já o utilizam confiando que sua "medição" está correta. Vergnaud (1993, p.3) coloca que "A confiabilidade do esquema para o sujeito baseia-se, em última análise, no conhecimento que ele possui, explícito ou implícito, das relações entre o algoritmo e o problema a resolver." Os alunos sabiam que para obter a medida solicitada bastava agir de determinada maneira e o faziam com bastante facilidade. Porém, não demonstravam segurança para justificar a diferença de valores encontradas pelos colegas.

Comparando as medidas encontradas percebeu-se que não havia sido definido o que registrar quando a medida não fosse um número exato de palitos e aí apareceram "quase 12 palitos" e "11 palitos e um pedaço" para a medida do banco, por exemplo. Também se constatou que a posição em que foram arranjados os palitos ou canudos pode ter sido a causa de pequenas diferenças (uma unidade) em algumas medidas. Os alunos comentaram que um grupo deixava espaço entre um canudo e outro; que outros alunos haviam colocado os canudos em "ziguezague" - como observamos na figura 1.
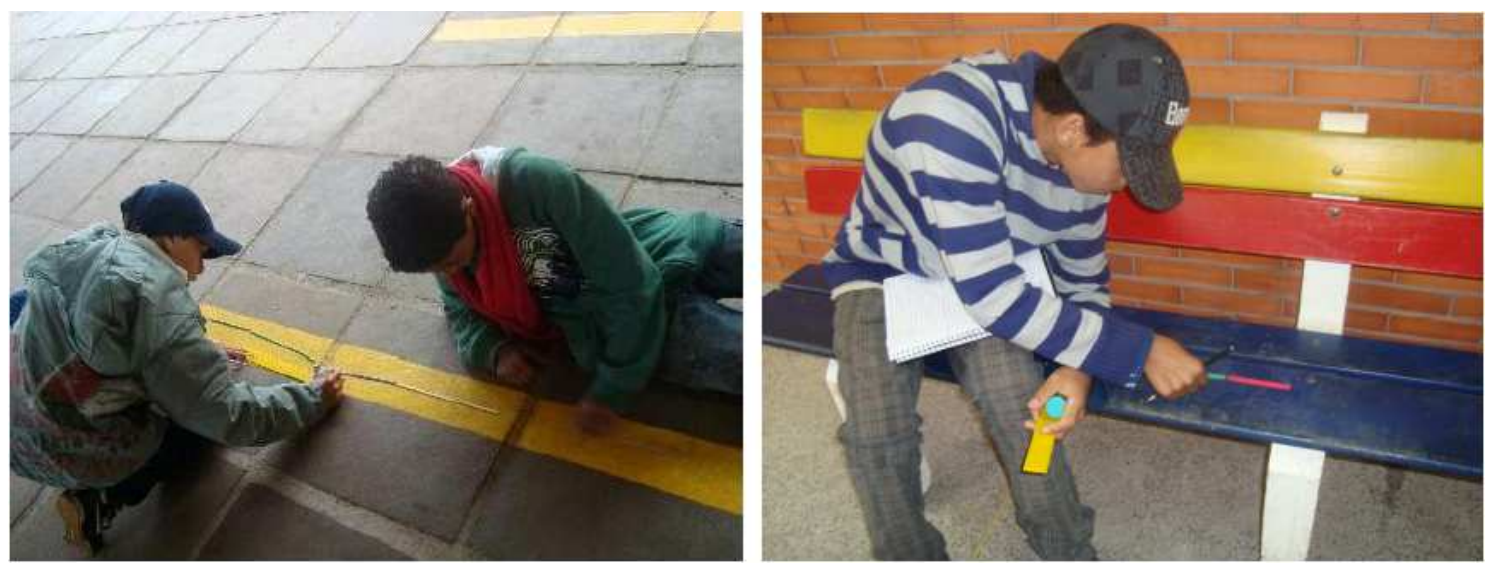

Figuras 1 e 2. Alunos trabalhando. Estas fotos mostram uma dupla medindo o comprimento da linha amarela com canudos e um aluno medindo o comprimento do banco com palitos.

Definido um esquema de ação para medir usando uma determinada unidade, o usos do objeto digital foi introduzido, como mostra a próxima sessão.

\section{Uso do recurso digital}


Chegando no Laboratório de Informática pôde se observar que, apesar de conhecerem alguns games, os alunos tinham pouca familiaridade com ferramentas simples. A primeira dificuldade foi digitar o endereço completo do site onde estava o objeto $^{2}$. Depois de encontrar o objeto, as instruções foram descobertas através da manipulação, pois pouquíssimos alunos recorreram ao link "instruções" onde as mesmas estavam descritas. Sabendo como funcionava o objeto era preciso resolver os oito desafios e registrar as respostas no caderno.

$\mathrm{O}$ objeto explorado foi o $\mathrm{BaBeBi}$, que apresenta uma linha e disponibiliza três unidades diferentes para medir o comprimento da mesma: $\mathrm{Ba}, \mathrm{Be}$ e Bi. Esse objeto foi desenvolvido pelo grupo MDMat- Mídias Digitais para Matemática com o objetivo de trabalhar unidades de medida não usuais com alunos de Ensino Fundamental. A concepção do objeto partiu de atividades realizadas com recursos não digitais e as transpôs para o computador. Essa característica torna o objeto acessível e sua manipulação quase intuitiva. Os mesmos esquemas de ação utilizados nos experimentos práticos são utilizados no Laboratório de Informática. Essa semelhança entre as tarefas concede mais uma chance àqueles que não compreenderam a tarefa anterior de vivenciar uma medição com unidades não-usuais, além de proporcionar a generalização do esquema de ação: usado com palitos, com canudos e agora em um objeto no computador.

Durante a exploração do objeto, o usuário mede arrastando as unidades e colocando-as sobre a linha, posteriormente, preenche com números a expressão “__ Ba $+\ldots$ Be + ___ Bi" e verifica se a medida informada está correta clicando no botão "Conferir". Na figura 3 é possível visualizar também o botão "girar", usado para colocar a unidade de medida na posição vertical, uma vez que todas aparecem na horizontal.

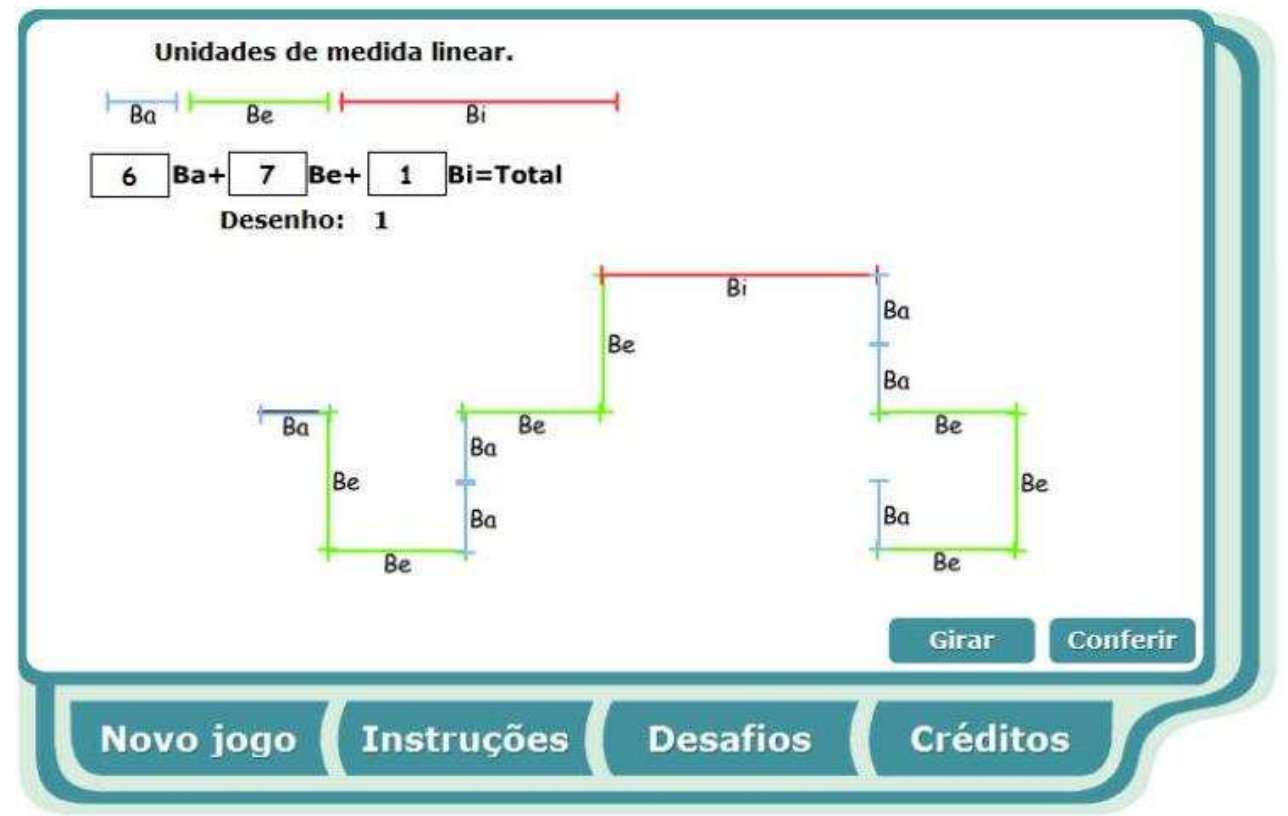

Figura 3. Interface do BaBeBi. Objeto com o primeiro desafio resolvido. A linha está sobreposta pelas unidades de medida disponíveis e a expressão que apresenta a medida do comprimento da linha está preenchida.

Uma diferença importante entre o objeto e os palitos e canudos é a possibilidade de utilização de três unidades distintas em uma mesma medição. É necessário cobrir a linha e

2 http://mdmat.mat.ufrgs.br/anos_iniciais

V. $9 \mathrm{~N}^{\mathrm{o}} 2$, dezembro, 2011 
registrar numericamente as unidades utilizadas, mas não é informada qual a unidade apropriada, permitindo que apareçam, como na figura 3, a utilização de todas as unidades. Essa característica será importante quando as unidades do SI estiverem sendo empregada, uma vez que $1,4 \mathrm{~m}$ é equivalente a 1 metro e 40 centímetros. Os alunos compreendiam que a linha medida tinha o comprimento de $6 \mathrm{Ba}+7 \mathrm{Be}+1 \mathrm{Bi}$ e que apenas os números não fariam sentido. Essa oportunidade de visualizar o resultado de uma medição como uma soma e não um único número traz sentido a afirmação "medida não é apenas um número, é preciso informar a unidade" proferida pela professora repetidas vezes.

Outros conceitos implícitos ao trabalho foram evidenciados na resolução de desafios específicos. Até o quinto desafio (linha) os alunos cobriam completamente a linha e depois contavam quantos $\mathrm{Ba}^{3}$, quantos $\mathrm{Be}$ e quantos $\mathrm{Bi}$ haviam sido utilizados e preenchiam a expressão. A partir da quinta linha alguns começaram a usar a intuição de paralelismo e segmentos congruentes. Assim, depois de medir uma parte da linha, identificavam os lugares onde se deveria utilizar a mesma medida e calculavam o número de $\mathrm{Ba}, \mathrm{Be}$ e $\mathrm{Bi}$ mentalmente. Quando se deram conta disso, bastava medir um pedaço e multiplicar a medida encontrada pelo número de vezes que ela aparecia.

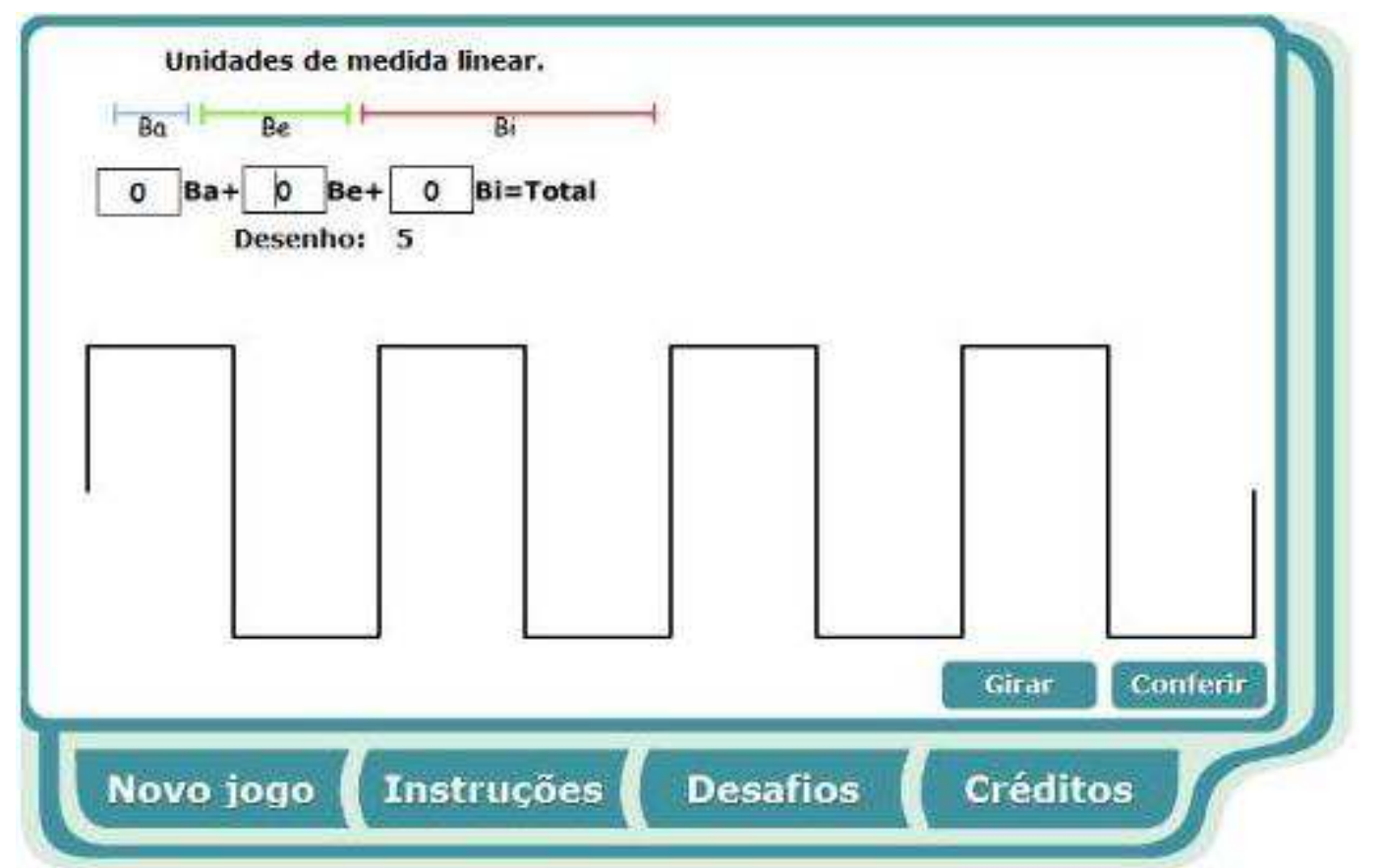

Figura 4. Desafio 5. Para resolver esse desafio os alunos mediam apenas os três primeiros segmentos e, por paralelismo, concluíam que os demais segmentos verticais eram idênticos e, por intuição, observavam que todos os segmentos horizontais tinham a mesma medida.

Com os registros, na sala de aula, a medida de cada uma das linhas foi corrigida e discutidos os motivos que poderiam ter causado as diferenças encontradas. Uma vez que o objeto informava se a medida estava correta como poderiam existir registros diferentes? Alguns alunos haviam esquecido de conferir e registraram no caderno informações erradas. Durante as correções surgiram respostas corretas diferentes. Foi então que as relações entre as unidades surgiram. Nesse objeto, um Be tem exatamente o mesmo comprimento que dois $\mathrm{Ba}$. E ainda, um Bi tem exatamente o comprimento de $2 \mathrm{Be}$ ou $4 \mathrm{Ba}$ ou $2 \mathrm{Ba}+1 \mathrm{Be}$. Esse foi o ponto de partida para a discussão sobre relações e, posteriormente, conversões entre diferentes unidades de medida. As relações entre a

3 As unidades de medida Ba, Be e Bi não são flexíveis em número - por definição. 
exploração dos recursos digitais e não-digitais estão expressas nas atividades de fechamento da proposta, tema a próxima sessão.

\section{Integração dos recursos e exploração dos conceitos}

$\mathrm{Na}$ sala de aula, resolvemos exercícios que usavam as mesmas unidades - e, assim, as mesmas relações - do objeto digital, mas sem utilizar o computador. Por exemplo, qual a medida equivalente a $3 \mathrm{Ba}+4 \mathrm{Be}+1 \mathrm{Bi}$ usando só $\mathrm{Ba}$ ? Ou então, quantos $\mathrm{Be}$ precisam ser alinhados para formar uma linha que tenha $6 \mathrm{Ba}+3 \mathrm{Be}+2 \mathrm{Bi}$ de comprimento? Nesse exemplo, as relações entre as unidades medidas são invariantes, uma vez que não se alteram na representação do computador ou do caderno. Para responder às questões propostas seria necessário operar com as unidades sem poder arrastá-las ou por tentativa e erro ${ }^{4}$. Foram utilizados desenhos representando as unidades e as trocas feitas entre unidades equivalentes para apresentar a solução numérica dos problemas, como mostra a figura 5 .

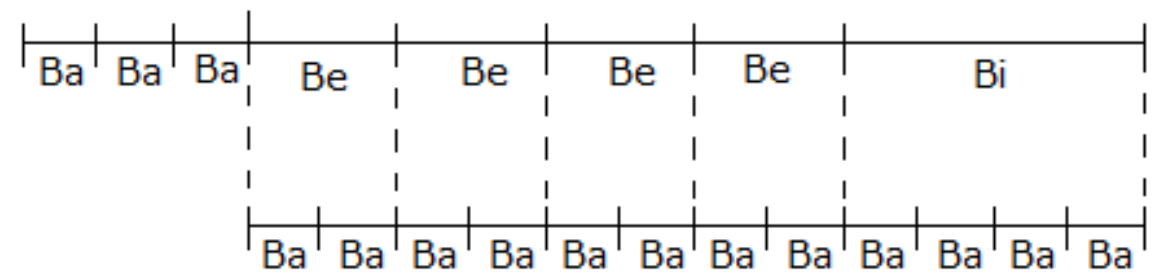

Figura 5. Esquema de Resolução. A figura é uma representação de uma das estratégias utilizadas pelos alunos para responder à pergunta "Qual a medida equivalente a $3 \mathrm{Ba}+4 \mathrm{Be}+1 \mathrm{Bi}$ usando só Ba?"

Os alunos resolveram equações como $13 \mathrm{Ba}+2 \mathrm{Be}=5 \mathrm{Ba}+16 \mathrm{Be}+\ldots \mathrm{Bi}$ sem que tenham ouvido ou utilizado a palavra equação. Isso foi possível porque os alunos tinham um esquema de ação para resolver esse problema. Mesmo sem o objeto digital eles eram capazes de operar com as unidades de maneira abstrata. A operação com o material já não era mais física e sim lógico-matemática. Não se manipulava o objeto em si, mas suas propriedades. As informações relevantes eram as relações entre as unidades e para completar a proposição era necessário manter o comprimento final invariante, variando somente as quantidades de cada unidade. Foi possível trabalhar com a validação das respostas obtidas a partir da argumentação, do uso de desenhos ou esquemas. Cada tarefa foi apresentada por um aluno que deveria explicar para os colegas como chegou à resposta. Essa exposição exigiu que os alunos se expressassem e colocassem em palavras o quê e como pensaram. Lovell $(1988$, p.14) coloca que

as crianças podem ter desenvolvido um conceito e ainda assim serem incapazes de definir o mesmo em termos verbais. Por outro lado, os professores são, muitas vezes, enganados porque as crianças podem usar a palavra apropriada e, apesar disso, não ter ideia do conceito relacionado.

O uso de estratégias erroneamente utilizadas apareceu nas explicações dos alunos e foi corrigido ou, pelo menos, apontado pelos colegas. Uma conversão foi feita sem obedecer à relação entre as unidades e a turma questionou quem apresentava a solução. Acrescenta-se que também foram questionados pelos colegas os alunos que resolveram as a tarefa relativamente rápido e que apresentaram dificuldade para explicar para a turma a estratégia adotada.

4 Estratégias utilizadas na exploração do objeto digital BaBeBi

V. $9 \mathrm{~N}^{\circ} 2$, dezembro, 2011 
Fagundes (1977, p. 6) diz que

A utilização de materiais concretos no ensino de $1^{\circ}$ Grau deve ser organizada de modo a propiciar a cada aluno situações de experiências físicas bem como situações de experiências lógico-matemáticas, onde ele possa realizar tanto abstrações empíricas quanto abstrações reflexivas.

Esse pensamento fez com que as atividades fossem elaboradas de forma que o que era aprendido em um determinado momento com um material pudesse ser transposto para outro na hora de realizar as tarefas. Ou seja, ter medido com palitos e canudos facilitou a medição com o objeto digital. Quem realizou as conversões entre $\mathrm{Ba}, \mathrm{Be}$ e $\mathrm{Bi}$ mais facilmente fez as relações entre palitos de picolé e canudos para verificar se as medidas apresentadas estavam coerentes.

Gaba (1975, apud Fagundes, 1977, p.1) propõe o seguinte esquema para a utilização de material concreto nas aulas de matemática:

Manipulação de objetos concretos
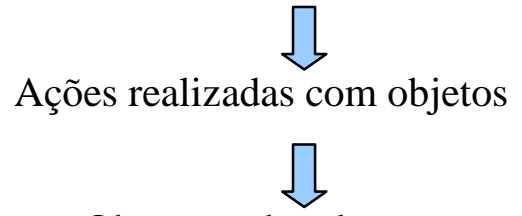

Obtenção de relações

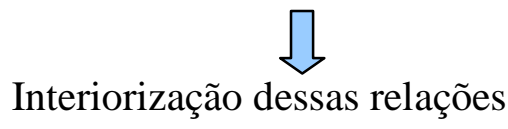

Aquisição e formulação do conceito

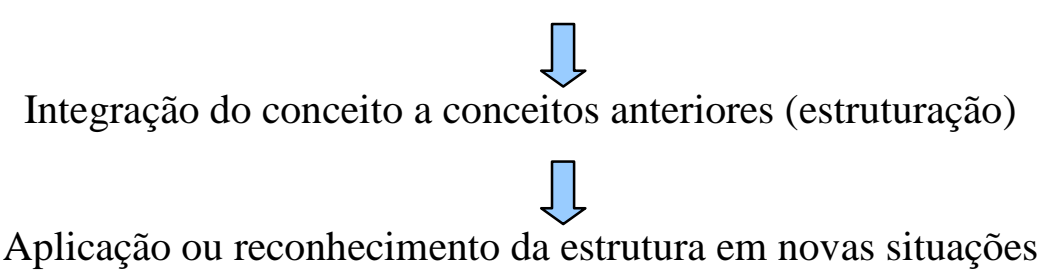

Esse esquema foi utilizado nessa proposta, mas não da maneira linear como é apresentado. Como foram utilizados diferentes materiais os alunos "iam e voltavam" por essas setas. Para cada unidade de medida (palito, canudo, $\mathrm{Ba}, \mathrm{Be}, \mathrm{Bi}$, centímetros, milímetros, metros) era preciso refazer o esquema. Essa possibilidade de recomeçar várias vezes permitiu aos alunos fazer as conexões entre os materiais e perceber, formular, compreender o conceito de medida, como mostram os resultados a seguir.

\section{Resultados e conclusões}

Um aluno que pergunta "Por que medir com palitos é colocar um ao lado do outro e na régua é olhar para o número que dá?" está manifestando que não compreende como a régua "mede". Medir é comparar uma unidade conhecida com a grandeza a ser medida, então para usar a régua é preciso, antes de tudo, definir a unidade que será utilizada. A unidade comumente utilizada quando se usa a régua é o centímetro. Quando os alunos visualizaram segmentos com um centímetro de comprimento alinhados ao longo da régua, como se fossem palitos de picolé, compreenderam porque se começa a 
medição no zero - não no um - e que os números impressos na régua representam a quantidade de segmentos alinhados até ali - para que não fosse necessário contar os intervalos todas as vezes.

Quando foram feitas as conversões entre as unidades do SI não se "decorou" a tabela com os múltiplos e submúltiplos do metro. Tampouco os alunos memorizaram a operação - divisão ou multiplicação - adequada para cada conversão. Ficou evidente, nas participações orais e nas tarefas resolvidas em aula, que os alunos pensavam no tamanho do metro e do centímetro e sabiam que o centímetro é menor e, por isso, terá de ser usado mais vezes. Certamente as relações $1 \mathrm{~cm}=10 \mathrm{~mm} ; 1 \mathrm{~m}=100 \mathrm{~cm} ; 1000 \mathrm{~m}=1 \mathrm{~km}$ tiveram que ser memorizadas. O "tamanho" do centímetro, do metro e do quilômetro, observado em diferentes situações fez com que os alunos não pensassem nas operações aritméticas a serem feitas e sim em uma nova medição a ser feita, com uma unidade maior ou menor.

Sendo assim, concluo que a variação de material possibilitou a formalização e trouxe naturalidade para que os alunos resolvessem os problemas propostos. Vivenciar situações e experimentos onde os invariantes são as características e os variantes são os valores encontrados abriu possibilidades de resolução de diferentes problemas. Permitir que os alunos que trabalhem com diferentes colegas ou sozinho, que formulem e testem suas próprias hipóteses, que discutam com colegas e apresentem seu modo de pensar para que seja avaliado pelo grupo de colegas foi uma maneira de trabalhar, além dos conteúdos matemáticos, autonomia, respeito, expressão oral, frustração e sentimento de conquista/descoberta. Apresentar alternativas diferente para as aulas proporcionou mais tempo de envolvimento e de interesse pelo trabalho por parte dos alunos, além de contemplar os interesses de cada um. Outros conteúdos que podem ser abordados dessa forma estão sendo estudados para que se possa testar essa estratégia com outras turmas e envolvendo ainda mais recursos.

\section{Referências}

FAGUNDES, Léa da Cruz. Materiais manipulativos no ensino de matemática a crianças de 7 a 14 anos - Período das operações concretas. 1977. Acesso online: <http://mdmat.mat.ufrgs.br/anos_iniciais/leituras/01_materias_manipulativos.pdf> Acessado em 02 de outubro de 2011.

HOFFMANN, Daniela Stevanin et al. Experiências física e lógico-matemática em Espaço e Forma: uma arquitetura pedagógica de uso integrado de recursos manipulativos digitais e não-digitais. XX Simpósio Brasileiro de Informática na Educação, Florianópolis, 2009.

LOVELL, Kurt. O desenvolvimento dos conceitos matemáticos e científicos na criança. Ed. Artes Médicas. Porto Alegre, 1988.

MARTINS, Elisa F. e FLORES, Gabriel W. (2009). BeBeBi. Objeto digital de aprendizagem. Disponível em:

<http://mdmat.mat.ufrgs.br/anos_iniciais/objetos/babebi.htm> Acessado em $02 \mathrm{de}$ outubro de 2011.

MDMat - Mídias digitais para Matemática. (2009) MDMat - Anos Iniciais Disponível em: <http://mdmat.mat.ufrgs.br/anos_iniciais> Acessado em 02 de outubro de 2011. 
PIAGET, Jean. O desenvolvimento das quantidades físicas na criança. Rio de Janeiro, Zahar, 1962.

VERGNAUD, Gerard. Teoria dos campos conceituais. In: Anais do $1^{\circ}$ Seminário Internacional de Educação Matemática do Rio de Janeiro, 1993, UFRJ. Rio de Janeiro: Projeto Fundão - Instituto de Matemática - UFRJ, 1993. p. 1-26. 